\title{
The potential of nutritional supplements: methyl donor rich food and their application in oncology
}

\author{
Dorottya Mühl*, Dénes Kleiner, Anett Hajdú, Éva Kiss, Marcell A Szász and Magdolna Dank \\ Semmelweis University Cancer Center, Hungary
}

*Corresponding author: Dorottya Mühl, Semmelweis University Cancer Center, 1085 Budapest, Tömő utca 25-29, Hungary

\begin{tabular}{|c|c|}
\hline ARTICLE INFO & ABSTRACT \\
\hline Received: 㠄 March 25, 2019 & Nowadays, a wide range of diets and dietary supplements are available for oncology \\
\hline Published: 慧 April 02, 2019 & $\begin{array}{l}\text { patients. As far as these products are concerned, mostly the beneficial effects of them are } \\
\text { promoted, but unfortunately, it is difficult to obtain valuable information about the actual }\end{array}$ \\
\hline $\begin{array}{l}\text { Citation: Dorottya M, Dénes K, Anett } \\
\text { H, Éva K, Marcell A S, Magdolna D. The } \\
\text { Potential Opportunities of Nutrition- } \\
\text { al Supplements: Methyl Donor Rich } \\
\text { Foods, and Their Potential Use in On- } \\
\text { cological Field. Biomed J Sci \& Tech Res } \\
\text { 16(4)-2019. BJSTR. MS.ID.002893. }\end{array}$ & $\begin{array}{l}\text { effects or potential dangers of these supplements, as these are not drugs, so different } \\
\text { quality requirements stated against compared to pharmaceuticals. This in itself raises } \\
\text { profound concerns about the potential harm of using such products, as in many cases } \\
\text { it is impossible to exactly know the content, and pollutants that can be found in these } \\
\text { supplements. During oncological treatment, patients often go for additional supplements } \\
\text { in the hope of healing. In most of the cases, this bears no harm, but there is minuscul } \\
\text { evidence of their positive effects. The aim of this study was to review the most frequently } \\
\text { used methyl-donors in oncological care, to present their chemical background, and give }\end{array}$ \\
\hline Abbreviations: ROS: Reactive Oxygen & practical examples based on available evidences. \\
\hline
\end{tabular}
Species; THF: Tertahydrofolate; MTHFR: Methyl-Tetrahydrofolate Reductase; SNP: Single Nucleoid Polymorphisms; MTR: Methyltrasferase; IF: Intrinsic Factor
Keywords: Nutrition; Supplements; Methyldonor; Redox Homeostasis; Anticancer Treatment

\section{Introduction}

Application of nutritional supplements raises many professional and moral questions beside treating cancer patients. Physicians are frequently asked about diets, and nutritional supplements in order to acquire valid information on them, by patients and their relatives. One of the most challenging hardships are the misbeliefs and myths surrounding nutritional supplements [1,2]. On the contrary with common beliefs these supplements can have negative effects too [3]. Even their authorization process is carried out by different professional procedures, compared to pharmaceutical products [1]. A formidable example for this is the commonly used A- vitamin, which is commonly used in these supplements in different amounts. As contrary to its known antioxidant effect, a potential overdose had been linked to help the formation of lung cancer (Figure 1). Or in another case, concerning overdose of folic acid, which again is commonly used by nutritional supplements can support the progression of colorectal cancer [4-6]. Although numerous professional studies suggests the potential benefit of folic acid in preventing colorectal cancer [7].

However, methyl-donors, vitamins, antioxidants, antocians, flavonoids are crucial parts of healthy body systems. These chemicals can be found mostly in fruits, vegetables, leguminous, oil seeds and in fish. In many cases as these pigmentous elements are responsible for characterizing the colors of fruits, vegetables (and others). From the perspective of a cancer patient, the highest effectiveness of the therapy, and decreasing the side effects can mean the greatest motivation for healing. From a professional perspective - according to our current knowledge - these supplements greatest impact can be in the decreasing of certain side effects [3]. Beyond a professional approach, it should be emphasized that nutritional supplements are falling into food category and should not be 
treated as pharmaceuticals when treating side effects. Meanwhile it is inarguable that well controlled doses indeed have beneficial effects on health [1]. The natural ingredients have beneficial effects in maintaining the natural balance of the body i.e.: supporting the body's symbiosis with microorganisms (Figure 2).

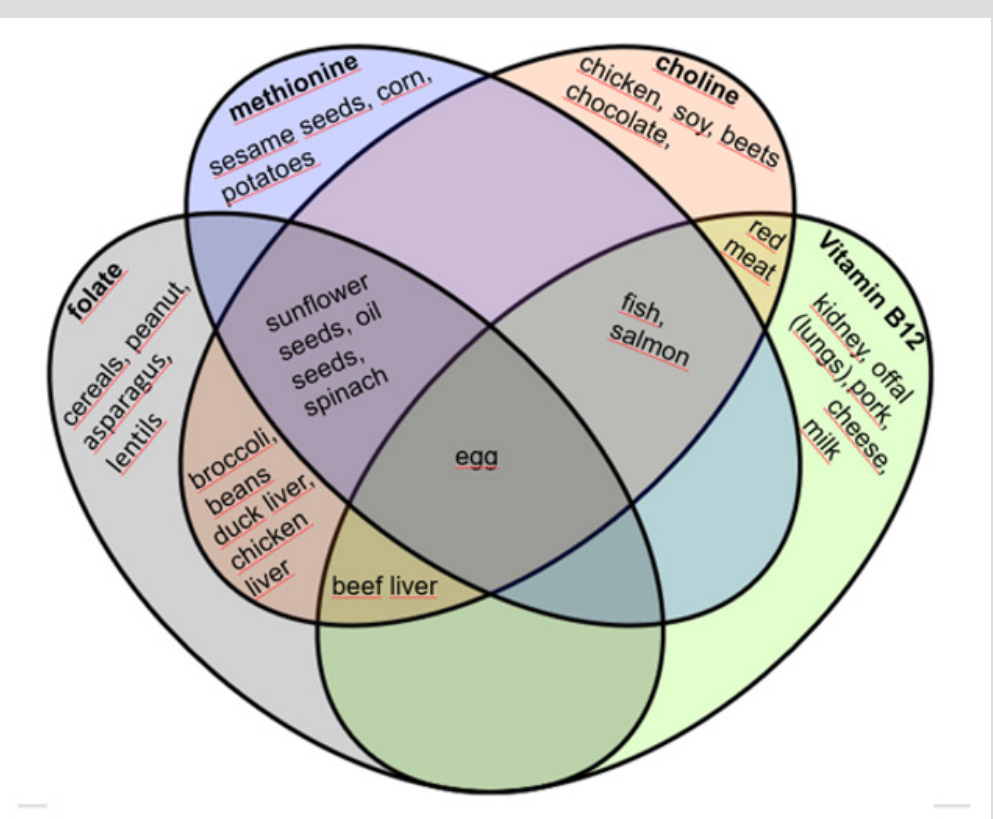

Figure 1: Figure food containing important methyl donors [45].

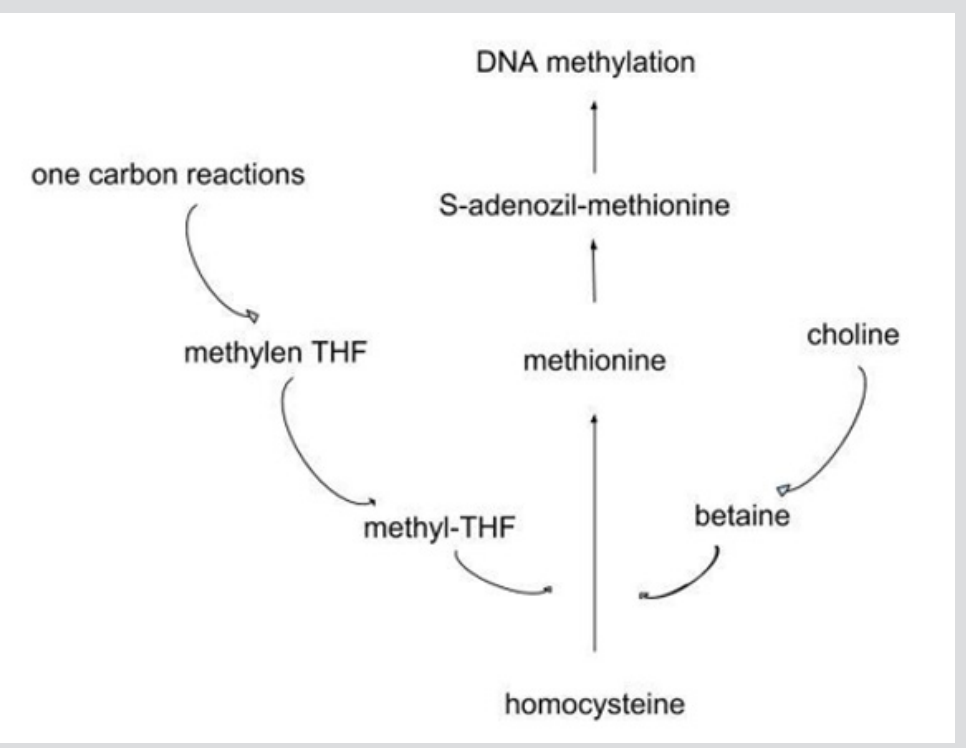

Figure 2: Activated methyl cycle.

This can be true for the composition of intestinal flora or for the nowadays commonly mentioned microbiome. The interaction of microbiome with the immune system has a significant role in facilitating antitumoral immune response, however it cannot be neglected that the probiotics can be contradicted in some case of immune supprimated patients [8,9]. The flavonoids in cherries and sour cherries contributes to mouth- and intestinal flora physiological working cycles $[10,11]$. When a cancer patient's balance during the treatment is pushed in the direction of pathogen flora, potentials of a sufficient diet can be unfolded. The most frequently used methyl donor compounds and their occurrence in different food can be seen on the first illustration.

\section{Biochemical Properties}

Before explaining the effects of each chemicals, it is important to introduce how complex is this biochemical system, which takes place within a cyclical metabolism as they all correspond each other. This is also the reason why this topic is so complex. The human body has well-constructed homeostasis, which is true for antioxidants - free radicals as well. The procedures can become 
unstable from both ways [12] but mostly in the direction of free radicals caused by outer/ inner stress related damages to human body (such as UV rays, radioactive waves, chronic inflammation, drugs etc.) which represent the oxidative ways. On the other hand, the exact opposite can happen, in connection with certain sicknesses, but in most cases its due to the overdose of nutritionalsupplements [13]. For the negative effects of upsetting the redox homeostasis in both sides, alcoholism draws a perfect example for reductive stress activity. Here next to the dangers of reactive oxygen species (ROS), the overpopulation of NADH (nicotinamide-adenindinucleotide) can be detected in the liver [14]. Here can be seen that some negative effects of alcohol can be derived from the so called reductive stress, of which we cannot hear from too often (Figure 3).

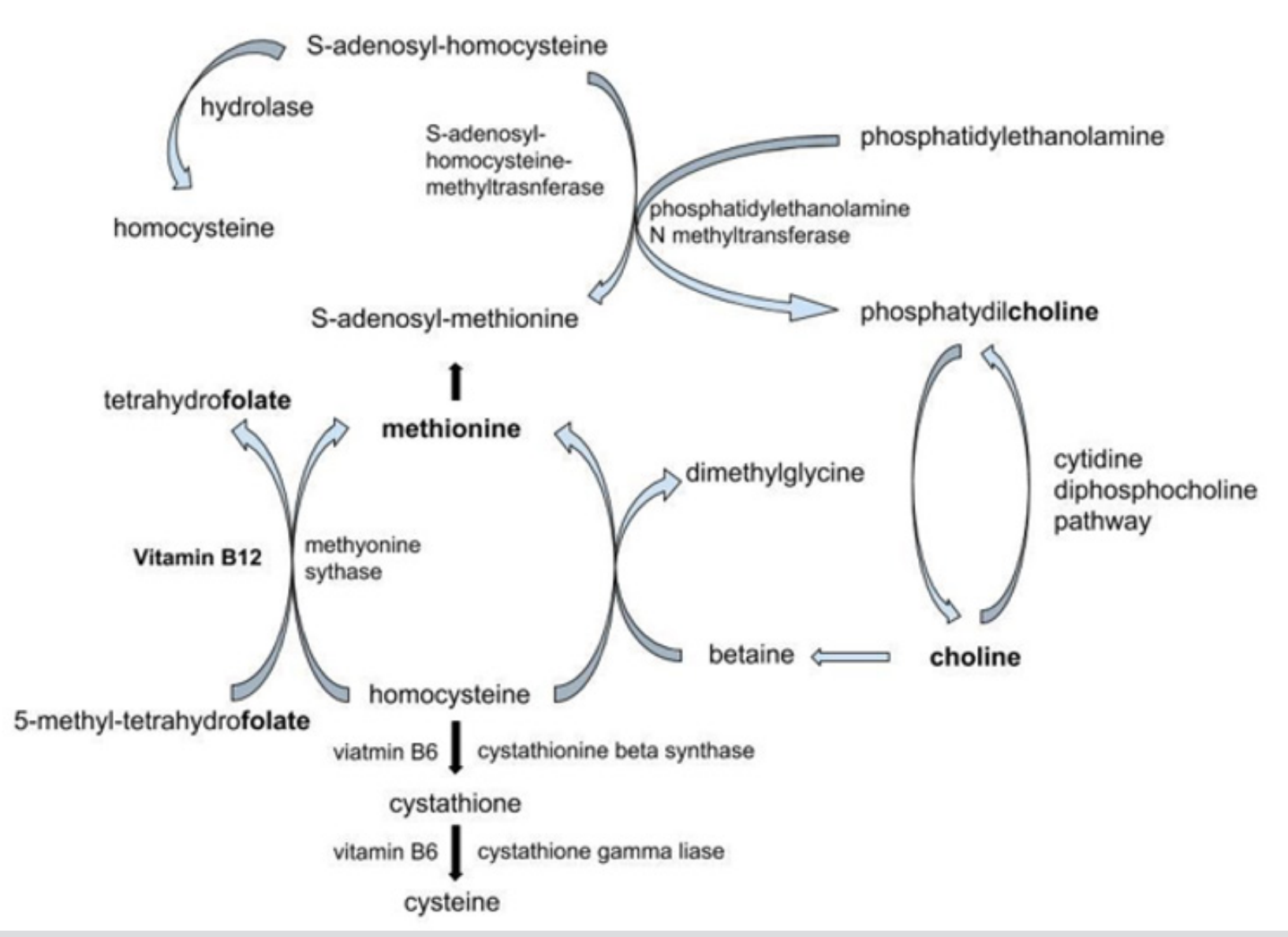

Figure 3: Main methyl donor interactions.

Moreover, there are antioxidant sicknesses, which did not spread due to ROS, but comes with the deficiency of the redox homeostasis. For instance, the Gilbert-syndrome which comes with and indirect hyperbilirubinemia. In this case the bilirubin quantity extends, which is an antioxidant chemical causing liver malfunction, and jaundice [15]. Hyperbilirubinemia can happen next to alcoholism too. The antioxidants usually neutralize free radicals in a way that themselves become free radicals after a while. However, having a slower reaction ability, in comparison to the starting out ROS. Therefore, the resulting free radicals have to be reduced, as at the end of the process non oxidative elements are formed [16]. A good example can be seen for the case of an antioxidant caused sickness at an examination of lung cancer. When treating lung cancer retinols progenies aka. isotretinoin plays a significant role (Figure 4). Due to these facts the possibility had been discussed to treat healthy patients with vitamin-A for preventative causes. In this study carotene given in overdosed amounts had increased the incidence of lung cancer ( daily need $900 \mu \mathrm{g}$ ). This study needed to be stopped. After long term inspections the morbidity and mortality for non-smokers had reduced to normal levels [4-6]. It is important to highlight, that during this research and immense amount of vitamin-A (20mg) had been used, so due to our knowledge nutritions and foods containing normal amount of vitamin-A have no adverse effects. 


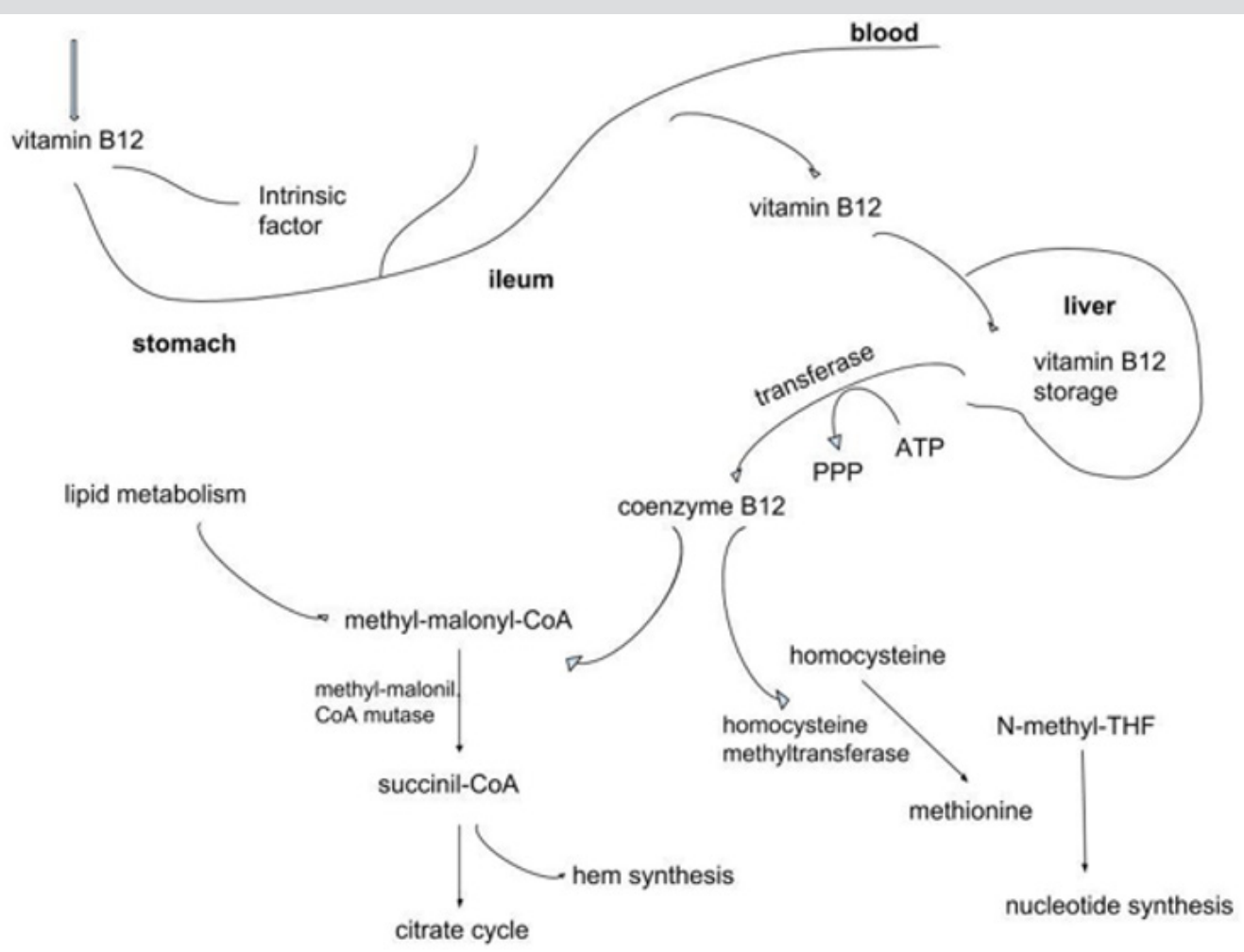

Figure 4: Metabolism of B12.

\section{More in Depth about the Methyl Procedures}

The methyl procedures are transferring methyl groups mostly in metabolic procecesses. It is called "one carbon metabolism". There is a crucial need for these fractions of carbon atoms in order to secure proper metabolism ie.: in digesting amino acids and producing nucleotides or carrying out post-synthetic modification of macromolecules (ie. Proteins, DNA, RNA). The environmental or epigenetical changes are mostly happen by these post-synthetic modifications $[17,18]$ For sufficient protein synthesis a normal DNA methylation is necessary. Methyl donors taken by food are mostly used in the tertahydrofolate (THF) or the S-adenosil-methionine (SAM) system [19]. The tetrahydrofolate system mostly receives it's methyl groups from serine and histidine, which transfers attached to nitrogen. Its task is to remethylate homocysteine to methionine with the methyl-tetrahydrofolate reductase (MTHFR) enzyme, which is one of the most important methyl donor component of the S-adenosil- methionine system [19,20]. The importance of MTHFR enzyme is that due to its postsynthetic modifications of the coding gene section (MTHFR gene) can be related to the carcinogenesis of colorectal carcinoma [21].

The rate limiting enzyme of the folate cycle is the MTHFR [19]. Some studies show that MTHFR can play a role at preventing colorectal carcinoma, it's exact role is still uncertain. There are some data which shows that dietary methionine, choline and folate intake can decrease the risk of CRC. Vogel et al found that folate intake increased the risk of CRC. Behind these findings, different single nucleoid polymorphisms (SNP) of MTHFR could stand [21].
The variants of MTHFR can be influenced by the acquired quantity of folic acid. In case of certain MTHFR SNPs a thermolabile enzyme is formed [22], which cannot catalyze sufficiently the homocysteine methionine reaction, therefore the body homocysteine level rises, which can be interrelated to tumor hypomethylation (especially in the case of CRC), heart and circulatory malfunctioning as well $[23,24]$.

SAM is one of the most important methyl group within the human body. During the activated methyl cycle (2.nd illustration) the chemical bonding between the methionine 's sulfur atom and the methyl group is weakened, therefore another bonding with a methyl acceptor can easily be done. From the sufficient functioning of the methyl-cycle the blood homocysteine level can give a reasonable information, because during the cycle s-adenozil-homocysteine is formed, and then following hydrolysis causes a homocysteine molecule. Later this can be used for cysteine synthesis or can be remethylated into methionine with the help of methyl-tetrahydrofolate homocysteine methyltrasferase (MTR) enzyme. However, if the rate limiting enzyme or coenzyme is missing, the whole process becomes slower, and the homocysteine will be piled up. For the accurate function of MTR, sufficient amount of THF (dietary folate) and B12 coenyzme is needed. When these two components are missing the methyl cycle cannot work properly [19].

\section{The Commonly used Chemicals by our Department}

Illustration 3 shows the most commonly found methyl-donors and their connections to each other. The well-known folic acid, as a food compound folate is contained by numerous products ( such 
as beans, lens, beef liver, spinach, asparagus, and cereals are all enriched by folic acid) the recommended daily intake is $400 \mu \mathrm{g} /$ day. Folates are reduced in several steps, therefore becomes the main component of methyl- tetrahydrofolate, which plays an essential role by transferring methyl groups. Folic acid deficit generally affects the third world, however individuals of developed countries can also suffer from it, if their diets do not contain adequate amount of folate eg. during pregnancy. Folic acid acquired from nutritional supplements have a higher bioavailability then from natural food products $[25,26]$. However, it is important to note that the overdose can be a significant problem as well. Certain studies shown that proper or at least not overdosed folate intake decreased the risk of CRC (less than or equal to $400 \mu \mathrm{g} /$ day). On the other hand, other researches had found that in case of already possessing precancerous status, the overdose of folic acid can increase the risk, or at least increase the disease progression of CRC especially at an older age.

Therefore, it is safe to say that a balanced folate rich diet (suppose with a diverse and proper diet) can decrease the risk of CRC, however in case of overdosing the adenoma carcinoma sequence can be strengthened and sped up [22,27]. Methionine is an essential amino acid, the human body is unable to produce it, therefore it has to be acquired from outer sources. Daily necessity demands around 2-3g, but for body builders and those who does physical work, these numbers should differ [28]. To produce methionine there is a need for methionine synthase which is a key enzyme at DNA methylation process. In case of some polymorphisms of this enzyme, the overdose of folates can increase the risk of CRC [29]. Its importance is in that methionine gives the mobile methyl group of SAM. SAM is one of the main methyl-group donors in the body. The choline is not considered as an essential amino acid, because the liver is able to produce a certain amount, however the majority of the necessary quantities are taken via eating. The daily required proportion is around $425 \mathrm{mg}$; however, choline deficit is so rare that the European Nutritional Committee has no official recommendation for the necessary amount [30].

It is the component of phosphatidyl-choline, which is responsible for building membranes and structure lipids. These molecules have amphipathic properties which means they have both hydrophile and hydrophobic parts. Ethanolamine is derived from serine by decarboxylation, and then from phosphatidi-etanolamine phosphatidil-kolin is produced meanwhile homocysteine is generated. SAM provides the necessary methyl group for the reaction. Furthermore, its importance is that choline is the precursor of betaine which is also responsible for some methyl donor functions $[19,31,32]$. Vitamin B12 or cobalamin is produced by different microorganisms, which can be consumed by a sufficient diet [33]. Daily need is $3 \mu \mathrm{g}$. Its importance is that during metabolic procedures it is functioning as a coenzyme. However, in order to be an effective coenzyme, it has to be in reaction with ATP in order to become B12coenzyme. It is the co-factor of homocysteine-methyltransferase in the SAM cycle. Lack of B12 can influence the nucleotid metabolism, anemia and methyl-malonil acidosis can be caused. B12 cannot be acquired without intrinsic factor (IF) in the stomach, therefore after removing the stomach by surgery substitution is very important [34]. Moreover, in the absence of it methyl-malonyl CoA-mutase cannot work further, therefore the methyl-malonyl is overpopulating, causing acidosis ( that's why absence of B12 vitamin can also cause acidosis) [19]. Illustration 4 shows the way of vitamin B12 in the body.

\section{Methyl-Donors in Oncological Diseases}

During chemotherapy numerous food which contain methyldonors are favored during the treatment. The beetroot is an excellent methyl-donors especially due to its high choline quantity, for its beneficial effects, patients consume them regularly. Studies proved its antitumoral activity in vitro [35]. It is digested by the colon's lower stage. Consuming large amount of beet root (or beet root extract) can discolor the colon causing "pulple colon" syndrome [36,37]. Their wastes also get discolored and this may can hide the villi. From red berries sour cherry showed good antioxidant properties. The containing flavonoids which can have anti-fungicide, antibacterial and antiviral effects, can be well applied for restoring intestinal- and mouth bacterial flora. During stomatitis, occurring next to cancer treatments sour cherry can have preventative effects. Frozen fruits next to the physical analgetic (freezing) attribution can restore oral mucosa, in patients suffering from neutropenia [38]. Another beneficial red berry is the red grape which has beneficial effects mainly due to resveratrole. It has a common anti-inflammatory effect due its COX-1enzyme inhibiton [39].

The suspected antitumoral effect is also due to COX-1 inhibiton. Studies shown that it could prevent tumor initiation and happened to be antimutagenic in vitro [40]. In the daily routine it is an anti-inflammatory product, however we have to take into consideration that it's bioavailability may vary individually [41]. A combination of vegetables and fruits shall be also emphasized, even if they are not strictly characterized as methyl-donors. Furthermore, they can be useful for patients receiving chemotherapy. This combination is the apple-carrot combo, which can greatly reduce chemotherapy side-effects such as diarrhea or constipation due to the apples' pectin levels [42]. Carotenoids have good effects due to their good antioxidant compounds [43]. As the patient is acquiring them in a normal amount and from natural food, there is no known risk of overdose.

\section{Conclusion}

By treating patients having a malignant tumor, it is difficult to define the proper role of different nutritional supplements, including their methyl-donor levels, as these supplements are immensely complex, and they do not undergo the same strict utilization process compared to pharmaceutical drugs. These nutritional supplements do not receive the same attention such 
as governmental supervision. Furthermore, it is difficult to measure the exact bioavailability especially, when several kinds of supplements are taken is the same time. However, they seem to be useful in treating side effects of chemotherapy, but it should be always taken into consideration that nutritional supplements are falling into food category. When applying dietary supplements, it is crucial to discuss procedures with nutritionist and it has to be specified individually at a multidisciplinary field, including physicians, nutritionist and pharmacist [44].

Due to the human body's regulatory systems, redox homeostasis is generally balanced, which should not be altered at all costs. In case of cancer patients this balance is immensely fragile, and unfortunately in many cases it only lasts for a short time. There is a need for precise monitoring, and screening if the assumptions are still necessary whether or not the side effects could be modulated [45]. These supplements can only be used next to the conventional treatment never instead of it. In case of a healthy individual there is only a small chance for deficiency in different nutrients or some deficiency symptoms. In case of deficiency, the missing compound must be restored, during a strict monitoring by a healthcare professional.

\section{Acknowledgements}

The work was supported by the NVKP_16-1-2016-0042 grant by the National Research, Development and Innovation Office of Hungary and AMS by the Bolyai Research Scholarship of the Hungarian Academy of Sciences.

\section{References}

1. (2018) Ogyéi. Étrend-kiegészítők.

2. (2013) Szövetsége MGO.

3. Harvie M (2014) Nutritional supplements and cancer: potential benefits and proven harms. Am Soc Clin Oncol Educ Book, pp. e478-486.

4. Lee JJ, Feng L, Reshef DS, Sabichi AL, Williams B, et al. (2010) Mortality in the randomized, controlled lung intergroup trial of isotretinoin. Cancer Prev Res (Phila) 3(6): 738-744.

5. (1994) The effect of vitamin $E$ and beta carotene on the incidence of lung cancer and other cancers in male smokers. N Engl J Med 330(15): 10291035.

6. Virtamo J, Pietinen P, Huttunen JK, Korhonen P, Malila N, et al. (2003) Incidence of cancer and mortality following alpha-tocopherol and betacarotene supplementation: a postintervention follow-up. Jama 290(4): 476-485.

7. Kim YI (2006) Folate: a magic bullet or a double edged sword for colorectal cancer prevention? Gut 55(10): 1387-1389.

8. Bhatt AP, Redinbo MR, Bultman SJ (2017) The role of the microbiome in cancer development and therapy. CA Cancer J Clin 67(4): 326-344.

9. Chen J, Pitmon E, Wang K (2017) Microbiome, inflammation and colorectal cancer. Semin Immunol 32: 43-53.

10. Haddad JJ, Ghadieh RM, Hasan HA, Nakhal YA, et al. (2013) Measurement of antioxidant activity and antioxidant compounds under versatile extraction conditions: II. The immuno-biochemical antioxidant properties of black sour cherry (Prunus cerasus) extracts. Antiinflamm Antiallergy Agents Med Chem 12(3): 229-245.
11. Hanbali LB, Ghadieh RM, Hasan HA, Nakhal Y, Haddad IJ (2013) Measurement of antioxidant activity and antioxidant compounds under versatile extraction conditions: I. the immuno-biochemical antioxidant properties of sweet cherry (Prunus avium) extracts. Antiinflamm Antiallergy Agents Med Chem 12(2): 173-187.

12. Ursini F, Maiorino M, Forman HJ (2016) Redox homeostasis: The Golden Mean of healthy living. Redox Biol 8: 205-215.

13. Tuboly E, Molnar R, Tokes T, Turányi RN, Hartmann P, et al. (2017) Excessive alcohol consumption induces methane production in humans and rats. Sci Rep 7(1): 7329.

14. Watson WH, Song Z, Kirpich IA, Deaciuc IV, Chen T, et al. (2011) Ethanol exposure modulates hepatic S-adenosylmethionine and S-adenosylhomocysteine levels in the isolated perfused rat liver through changes in the redox state of the NADH/NAD(+) system. Biochim Biophys Acta 1812(5): 613-618.

15. Strassburg CP (2010) Hyperbilirubinemia syndromes (GilbertMeulengracht, Crigler-Najjar, Dubin-Johnson, and Rotor syndrome). Best Pract Res Clin Gastroenterol 24(5): 555-571.

16. Szőke Éva, Balázs Andrea, Blázovics Anna, Kéry Ágnes, Kursinszki László, et al. (2012) Gyógynövény és Drogismeret Farmakognózia - Fitokémia, gyógynövények alkalmazása. Semmelweis Egyetem.

17. Quach A, Levine ME, Tanaka T, Lu AT, Chen BH, et al. (2017) Epigenetic clock analysis of diet, exercise, education, and lifestyle factors. Aging (Albany NY) 9(2): 419-446.

18. Sae Lee C, Corsi S, Barrow TM, Kuhnle GGC, Bollati V et al. (2018) Dietary Intervention Modifies DNA Methylation Age Assessed by the Epigenetic Clock. Mol Nutr Food Res 62(23): e1800092.

19. Veronika Á, László D, Anna F (2004) Biochemistry. [Orvosi Biokémia]. Medicina Kiadó.

20. Li F, Feng Q, Lee C, Wang S, Pelleymounter LL, et al. (2008) Human betaine-homocysteine methyltransferase (BHMT) and BHMT2: common gene sequence variation and functional characterization. Mol Genet Metab 94(3): 326-335.

21. De Vogel S, Wouters KA, Gottschalk RW, Frederik J Van Schooten, Anton FP M De Goeij, et al. (2011) Dietary methyl donors, methyl metabolizing enzymes, and epigenetic regulators: diet-gene interactions and promoter $\mathrm{CpG}$ island hypermethylation in colorectal cancer. Cancer Causes Control 22(1): 1-12.

22. Ashmore JH, Lesko SM, Muscat JE, Gallagher CJ, Berg AS, et al. (2013) Association of dietary and supplemental folate intake and polymorphisms in three FOCM pathway genes with colorectal cancer in a population-based case-control study. Genes Chromosomes Cancer 52(10): 945-953.

23. Liu Z, Cui C, Wang X, Alejandro Fernandez Escobar, Qunzheng Wu, et al. (2018) Plasma Levels of Homocysteine and the Occurrence and Progression of Rectal Cancer. Med Sci Monit 24: 1776-1783.

24. Mccully KS, Wilson RB (1975) Homocysteine theory of arteriosclerosis. Atherosclerosis 22(2): 215-227.

25. Suitor CW, Bailey LB (2000) Dietary folate equivalents: interpretation and application. J Am Diet Assoc 100(1): 88-94.

26. Guerreiro CS, Carmona B, Goncalves S, Carolino E, Fidalgo P, et al. (2008) Risk of colorectal cancer associated with the C677T polymorphism in 5,10-methylenetetrahydrofolate reductase in Portuguese patients depends on the intake of methyl-donor nutrients. Am J Clin Nutr 88(5): 1413-1418.

27. Pufulete M, Emery PW, Sanders TA (2003) Folate, DNA methylation and colo-rectal cancer. Proc Nutr Soc 62(2): 437-445.

28. (2018) USDA. Food Composition Databases.

29. Yamaji T, Iwasaki M, Sasazuki S (2009) Methionine synthase A2756G polymorphism interacts with alcohol and folate intake to influence the risk of colorectal adenoma. Cancer Epidemiol Biomarkers Prev 18(1): 


\section{7-274.}

30. Hivatal EÉ (2018) European Food Safety Authority.

31. Lee JE, Giovannucci E, Fuchs CS, Willett WC, Zeisel SH, et al. (2010) Choline and betaine intake and the risk of colorectal cancer in men. Cancer Epidemiol Biomarkers Prev 19(3): 884-887.

32. (2019) University OS and Institute LP. Micronutrient Information Center.

33. Gille D, Schmid A (2015) Vitamin B12 in meat and dairy products. Nutr Rev 73(2): 106-115.

34. Chhikara N, Kushwaha K, Sharma P, Gat Y, Panghal A, et al. (2019) Bioactive compounds of beetroot and utilization in food processing industry: A critical review. Food Chem 272: 192-200.

35. Lechner JF, Wang LS, Rocha CM, Larue B, Henry C, et al. (2010) Drinking water with red beetroot food color antagonizes esophageal carcinogenesis in N-nitroso methylbenzylamine-treated rats. J Med Food 13(3): 733-739.

36. Cserni G, Kocsis L (2008) The case of the purple colon. Virchows Arch 452(6): 703 .

37. Blazovics A, Kursinszki L, Papp N, Kleinera D, Szőke E, et al. (2016) Is professional prescription of a commercially derived dietary supplement in colectomysed patients necessary? European Journal of Integrative Medicine 8(3): 219-226.

\section{ISSN: 2574-1241}

DOI: 10.26717/BJSTR.2019.16.002893

Dorottya Mühl. Biomed J Sci \& Tech Res

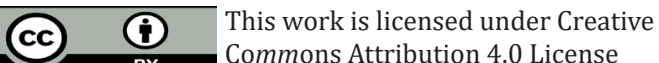

Submission Link: https://biomedres.us/submit-manuscript.php
38. Bak I, Lekli I, Juhasz B, Varga E, Varga B, et al. (2010) Isolation and analysis of bioactive constituents of sour cherry (Prunus cerasus) seed kernel: an emerging functional food. J Med Food 13(4): 905-910.

39. Plauth A, Geikowski A, Cichon S, Wowro SJ, Liedgens L, et al. (2016) Hormetic shifting of redox environment by pro-oxidative resveratrol protects cells against stress. Free Radic Biol Med 99: 608-622.

40. Jang M, Cai L, Udeani GO, Slowing KV, Thomas CF, et al. (1997) Cancer chemopreventive activity of resveratrol, a natural product derived from grapes. Science 275(5297): 218-220.

41. Azachi M, Yatuv R, Katz A, Hagay Y, Danon A, et al. (2014) A novel red grape cells complex: health effects and bioavailability of natural resveratrol. Int J Food Sci Nutr 65(7): 848-855.

42. Mardas M, Madry R, Stelmach Mardas M (2017) Link between diet and chemotherapy related gastrointestinal side effects. Contemp Oncol (Pozn) 21(2): 162-167.

43. Gaffey MF, Wazny K, Bassani DG, Zulfiqar A Bhutta (2013) Dietary management of childhood diarrhea in low- and middle-income countries: a systematic review. BMC Public Health 13(Suppl 3): S17.

44. Lugasi A, Horacsek M, Martos E (2010) [Food supplements on the domestic market in Hungary: nutritional assessment of the ingredients, risks and benefits, the role of food supplements in human nutrition]. Orv Hetil 151(48): 1964-1975.

45. Imre R (2005) Új tápanyagtáblázat. Medicina Könyvkiadó.

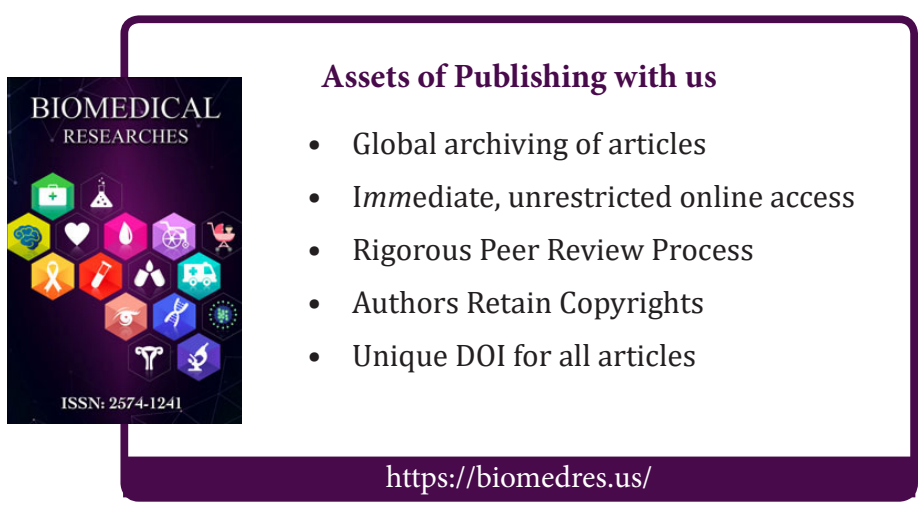

